\title{
Barriers to the Uptake of Biosimilars and Possible Solutions: A Belgian Case Study
}

\author{
Pieter Dylst · Arnold Vulto $\cdot$ Steven Simoens
}

Published online: 7 May 2014

(C) Springer International Publishing Switzerland 2014

\begin{abstract}
Background Biosimilars are medicinal products that are similar to a biopharmaceutical that has already been authorised. As biopharmaceuticals are expected to dominate the best-selling pharmaceuticals worldwide by 2016, the emergence of biosimilars imposes an important challenge for governments. At this moment, the uptake of biosimilars in Belgium is limited, with market shares close to $0 \%$.

Objective This study aimed to identify the barriers that impede the uptake of biosimilars in Belgium.

Methods Semi-structured interviews were conducted to investigate in depth the barriers to the uptake of biosimilars in Belgium. Respondents were selected through selective sampling so that all different stakeholders were represented (authorities, physicians, pharmacists, patients, academics and industry). Respondents were contacted by e-mail and letter with a request for participation. A thematic framework was used to analyze the data.
\end{abstract}

Electronic supplementary material The online version of this article (doi:10.1007/s40273-014-0163-9) contains supplementary material, which is available to authorized users.

\section{P. Dylst $\cdot$ S. Simoens $(\square)$}

KU Leuven, Department of Pharmaceutical and Pharmacological

Sciences, Herestraat 49, O\&N 2, P.O. Box 521, 3000 Leuven,

Belgium

e-mail: steven.simoens@pharm.kuleuven.be

P. Dylst

e-mail: pieter.dylst@pharm.kuleuven.be

\section{A. Vulto}

Hospital Pharmacy, Erasmus University Medical Centre,

Rotterdam, The Netherlands

e-mail: a.vulto@erasmusmc.nl
Results Three main barriers to the uptake of biosimilars in the Belgian market were identified: a lack of confidence towards biosimilars by some stakeholders; uncertainty about the interchangeability and substitution of biosimilars; and a hospital financing system that discourages the use of them. Providing all stakeholders with objective information on the concept of biosimilars, reforming the financing of hospitals, developing and implementing prescription quota in hospitals, setting up patient registries for biosimilars and speeding up the pricing and reimbursement process of biosimilars are suggested solutions to increase the uptake of biosimilars in Belgium.

Conclusions To fully capture the potential savings of biosimilars, governments should take measures to increase their uptake. The Belgian government, and also the manufacturers of biosimilars, should take measures to reduce the uncertainties related to biosimilars and raise confidence among prescribers. In addition, the financing of hospitals should be reformed and incentives should be developed to stimulate physicians to prescribe biosimilars. 


\section{Key Points for Decision Makers}

Biopharmaceuticals are expected to dominate the best-selling pharmaceuticals worldwide by 2016

The emergence of biosimilars, which are similar to a biopharmaceutical that has already been authorised, imposes an important challenge for governments

Uncertainties surrounding biosimilars, resulting in impaired confidence by physicians and patients, are an important barrier to the uptake of biosimilars

To increase the uptake of biosimilars, governments and companies producing biosimilars should inform all stakeholders on the concept of biosimilars to reduce the uncertainties

Incentives to prescribe biosimilars should be developed as physicians are unlikely to change their prescribing behavior without them

\section{Introduction}

The importance of biotechnological medicines or biopharmaceuticals has increased over the past decade, with worldwide sales almost doubling from US $\$ 63.8$ billion in 2006 to US\$124.6 billion in 2012 [1, 2]. By 2016, biopharmaceuticals are expected to dominate the top ten of the best-selling pharmaceuticals worldwide by seven out of ten [3]. The expiration of data protection and patents on the first biopharmaceuticals have opened up the market for copy versions, so-called similar biological medicinal products or biosimilars, previously also known as follow-on biologics in the US.

Biopharmaceuticals are produced out of cultures of living cells and therefore are more complex molecules than small, chemically synthesized medicines. The complexities in their manufacturing process (e.g. type of expression system, growth conditions, purification process, actual formulation, conditions during storage and transport, etc.) also make it impossible to produce identical products [4-6]. Different batches of the same originator biopharmaceutical may even have a certain degree of variability [7]. The complexity of these products made the development of a specific regulatory pathway for biosimilars necessary (i.e. legal framework, general and product-specific guidelines or guidance), as that of generic medicines seemed to be insufficient.

The European Commission was at the forefront of the development of a specific regulatory pathway for biosimilars and introduced a legal framework in 2003, the socalled 'biosimilar pathway' [8-10]. A biosimilar is defined by the European Medicines Agency (EMA) as "a product which is similar to a biological medicine that has already been authorized, the so-called 'reference medicinal product'. The active substance of a similar biological medicinal product is a known biological active substance and similar to the one of the reference medicinal product." [11]. Unlike generic medicines, biosimilars do not have to be strictly identical to their originator equivalents and thus may have a certain degree of variability, as defined in the guidelines. Similar to all biotechnology-derived medicinal products in the EU, biosimilars are, by law, reviewed centrally by the EMA. Both general and product-specific guidelines have been released by the EMA to assist and guide applicants through the registration procedure.

In the US, a legal framework for biosimilars was only introduced in 2012 by the Biologics Price Competition and Innovation Act (BPCIA). This act introduced an abbreviated approval process for follow-on biologic products in the US (i.e. Abbreviated Biologics License Application, or ABLA), which was previously missing $[10,12]$. Biosimilar or biosimilarity has been defined in the US to mean that "the biological product is highly similar to the reference product notwithstanding minor differences in clinically inactive components," and that "there are no clinically meaningful differences between the biological product and the reference product in terms of the safety, purity, and potency of the product" [13]. Despite the legal framework, there is still work to be done as in 2012 only four biosimilar implementation guidelines have been released by the US FDA [14].

Biosimilars in both the EU and the US have to demonstrate comparable quality, safety, efficacy, and tolerability (i.e. risk on immunogenicity) of the biosimilar compared with the reference product. Applicants may therefore partly rely on clinical data of the reference product but still have to perform clinical trials, albeit not as extensive as the reference product, to ensure that small differences do not affect the clinical profile of the medicine. Just like the reference biopharmaceutical, biosimilar applicants are required to provide a risk management or pharmacovigilance plan, taking into account potential risks $[6,9,15]$. This is in great contrast with generic medicines, which only have to demonstrate pharmaceutical equivalence (i.e. identical active substances) and bioequivalence (i.e. comparable pharmacokinetics) and may rely on all clinical safety and efficacy data of the originator medicine $[15,16]$. It is thus important to stress that biosimilars should not be regarded simply as generic versions of biopharmaceuticals, and therefore the use of the expression 'bio-generic' is inappropriate [4]. The regulatory pathways governing biosimilars differ somewhat between the EU and the US. The main differences are related to exclusivity periods, consideration of substitution and interchangeability, and necessity of postmarketing monitoring of risks 
[15]. This need to demonstrate interchangeability in the US may become a major stumbling block for their registration as it will likely require costly switch trials.

The development of a biosimilar is thus a more complex time- and cost-consuming process than the development of a generic medicine $[3,15]$. The development cost of a biosimilar, for instance, is estimated between US\$75 million and US $\$ 250$ million, whereas this is only between US\$1 million and US\$5 million for a generic medicine $[17,18]$. As a result, price differences between biosimilars and their reference product are estimated to be only between 15 and $30 \%$, whereas this can be as high as $80 \%$ for generic and originator medicines $[15,19,20]$. Biosimilars, however, still attract the attention of governments and health care payers. The high prices of treatment with biopharmaceuticals and their enormous impact on pharmaceutical budgets mean that biosimilars can contribute considerably to containing expenditures on biopharmaceuticals as the percentually small price difference will add up to large sums of money [21]. By 2020, for instance, 12 blockbuster biopharmaceuticals, with global sales worth over US $\$ 67$ billion, will be exposed to competition by biosimilars [22]. A calculation of possible savings from biosimilars in eight European countries estimated their savings potential between $€ 11.8$ and 33.4 billion between 2007 and 2020 [20]. The experience with the first generation of biosimilars has shown that biosimilars have also induced significant price reductions for innovator medicines. This shows the importance for governments to develop a coherent policy to stimulate the uptake of biosimilars in order to increase patient access to more affordable biopharmaceutical therapies while maintaining high-quality standards, especially in times when there is rising pressure on pharmaceutical expenditures.

The first biosimilars in the EU have received a marketing authorization in 2006 and since then 14 biosimilars have been approved by the EMA in three different product classes: five erythropoiesis-stimulating agents (epoetins), seven granulocyte-colony stimulating factors (filgrastims), and two growth hormones (somatropin) [23, 24]. In June 2013, the Committee for Medicinal Products for Human Use (CHMP) of the EMA adopted a positive opinion, recommending the granting of a marketing authorization, for the first two biosimilar monoclonal antibodies, which have shown to be similar to infliximab [25]. In the US, no biosimilar has been approved by the FDA to date. The lack of a specific regulatory pathway for biosimilar medicines has urged pharmaceutical companies to use other strategies. Several off-patent versions of low-molecular-weight heparins, insulin, glucagon, and human growth hormones (somatropin) have been approved and marketed in the US by an Abbreviated New Drug Application (ANDA), which is the procedure for generic medicines [26]. Another biopharmaceutical, Teva's filgrastim (Tbo-Filgrastim ${ }^{\circledR}$ ), which is similar to Amgen's filgrastim (Neupogen ${ }^{\circledR}$ ), has been approved and marketed by a Biologics License Application (BLA), which is the procedure for original biopharmaceuticals. In contrast, the same product has been marketed by Teva in Europe as a biosimilar filgrastim $\left(\right.$ Tevagrastim $\left.{ }^{\circledR}\right)$ [17].

In Belgium, only five biosimilars are currently on the market (i.e. two epoetins, one somatropin, and two filgrastims) [24, 27]. Whereas the uptake of biosimilars by volume in many European countries is well above $20 \%$, the uptake in Belgium is close to $0 \%$, as explained below [28-31]. The sales of biosimilars in Belgium are also generated for only one active substance (i.e. somatropin), despite the presence of biosimilars in three different product classes [24].

Previous research has shown that the choice of a physician to make use of a new innovation (i.e. a biosimilar in this case) is determined by five key innovation criteria: relative advantage (i.e. the degree to which an innovation is perceived as better than its predecessor); compatibility (i.e. the degree to which an innovation is perceived as being consistent with the existing values, past experiences, and needs of potential adopters); complexity (i.e. the degree to which an innovation is perceived as being difficult to use); trialability (i.e. the degree to which an innovation may be experimented with on a limited basis before adoption), and observability (i.e. the degree to which the results of an innovation are observable to others). Meeting these adoption criteria could positively influence the future success of the development of biosimilars [32]. This also offers a theoretical framework to evaluate the situation in Belgium and which actions can be taken to improve the uptake of biosimilars in Belgium.

The aim of this study was to identify barriers to the uptake of biosimilars in Belgium. Possible solutions to increase the uptake of biosimilars in Belgium are suggested at the end of the article.

\section{Methods}

This study used qualitative research methods as this would enable researchers to investigate in depth the barriers to the uptake of biosimilars in Belgium. Semi-structured interviews were used as they enable the interviewer to elaborate on specific aspects or insights of the interviewee or when certain aspects are unclear for the researcher.

\subsection{Participants}

A total of 74 persons were contacted by both e-mail and letter to participate in this study. Respondents were 
identified through selective sampling so that all relevant stakeholders were represented: authorities (sickness funds, regulator, members of the Belgian Drug Reimbursement Committee); physicians; pharmacists; patients (i.e. patient organizations); academics; industry originator; industry biosimilar; and industry combined. Only stakeholders with supposed experience with biopharmaceuticals were contacted for participation.

\subsection{Data Collection}

Semi-structured interviews were conducted during the period October 2012-February 2013 by a group of five pharmacy students supervised by SS and PD. Respondents who indicated they were willing to participate in the interviews were contacted by e-mail for further arrangements concerning time and place of the interview. If requested by the interviewee, the semi-structured interview guide was sent in preparation of the interview.

A semi-structured interview guide was drafted based on topics derived from a literature review that was part of a previous project of the group of five pharmacy students (see electronic supplementary material). Three experts on biosimilars were given the opportunity to comment on the content validity of this semi-structured interview guide, after which it was adapted according to their comments.

The respondents participated voluntarily and were not remunerated. No approval from a research ethics committee was required because of the nature of the interviews. The purpose of the study was explained at the beginning of the interview, while the anonymity of participants and confidentiality of the answers were guaranteed. The interviews were digitally recorded to facilitate the processing of the results afterwards.

The interview started with some general questions about the role of the interviewee and their knowledge on biosimilars. Further on, different topics were discussed, such as the development, registration, pricing, reimbursement, prescribing, and dispensing of biosimilars in Belgium. According to the characteristics of the interviewee, some aspects were skipped while other aspects were more elaborated on.

\subsection{Data Analysis}

The interviews were analyzed according to the five stages of the framework analysis described by Pope and Mays [33]: (i) familiarization (reading of the transcripts and notes, listening to the digital recordings); (ii) identifying a framework; (iii) indexing (application of the framework to the data); (iv) charting; and (v) mapping and interpreting. As there was already a certain understanding of the issue in advance of the analysis, a thematic framework was used. A thematic framework was built by the students involved in the study, based on previously identified main issues as well as issues emerging from the data. The interviews were analyzed using the software QSR NVivo 9 to facilitate the analysis [34].

Two interviews were conducted in English, therefore no translation of those quotes was needed. The selected quotes of the other interviewees were translated as accurate as possible.

\section{Results}

In total, 22 of 74 persons responded to our e-mail or letter to participate in the study. Three persons ultimately decided to dropout after receipt of the interview guide: one person due to a lack of expertise on the topic; one person because of doubts about the added value of the interview for the study; and one person because of a lack of time. This resulted in 19 persons participating in the interviews. All categories of stakeholders were represented and participants were coded according to their function, as shown in Table 1.

\subsection{Lack of Confidence Towards Biosimilars}

All interviewees acknowledged that a lack of confidence in biosimilars by some stakeholders is one of the main barriers to the uptake of biosimilars in Belgium. This lack of confidence was most pronounced by physicians and representatives of the originator industry, who tended to question biosimilars on different aspects such as quality, safety, and interchangeability.

"The perceptions of biosimilars in general, whether or not sustained by the originator industry, are: is the

Table 1 Classification of interviewees according to their function (number of interviewees)

\begin{tabular}{cl}
\hline Interviewee & Professional function \\
\hline Aut (1-4) & Authority \\
Aut 1: & Representative of sickness funds \\
Aut 2: & Regulator \\
Aut 3-4: & Member of Belgian Drug Reimbursement Committee \\
Aca (1-3) & Academic \\
IO (1-2) & Industry originator \\
Phy (1-2) & Physicians \\
Pha (1-3) & Pharmacist \\
Pat (1) & Patient \\
IB (1-3) & Industry biosimilar \\
IOB (1) & Industry combined \\
\hline
\end{tabular}


quality of biosimilars sufficient, are these products of equal quality?" (Aut4).

"For biosimilars, there is a similar reluctance among physicians. In the sense that we can have doubts about whether or not they are identical to the parent product. And there is still fear of a wider quality tolerance for biosimilars, because the production process is much more complex of course." (Phy1)

Most interviewees acknowledged their trust in the EMA and their registration procedures, except some physicians who tended to distrust the EMA and their procedures for biosimilars. Product-specific guidelines for biosimilars were seen as a positive point by all stakeholders. A possible need for even more specific and clear guidelines, however, was voiced by representatives of the authorities.

"I think it's helpful for the companies developing medicinal products, for them to have also specific guidelines. Because the companies actually like the guidelines, in my experience ...' (Aca1)

"So you have so many different types of biologicals: blood factors, monoclonal antibodies, proteins, enzymes, etc., which of course must be adapted to the needs of the scientific guidelines and the scientific aspects ..." (IO2)

"Guidelines actually ensure that it is actually clear for the companies what we need to do. And for the government they know what they can expect." (IB1)

"We see the same questions coming back regularly.

There is a clearly need for more guidelines, also product-specific guidelines" (Aut2).

Physicians' lack of confidence in biosimilars could be explained by a knowledge gap, which in turn may be caused by an 'information gap'. Whereas manufacturers of the reference product spent large amounts of money on marketing and informing physicians and patients on their products, manufacturers of biosimilars generally do not make those efforts. They have, however, acknowledged this shortcoming and have said to be working on it:

“... There is a huge lack of information for doctors and pharmacists ..." (IB3)

"... The companies that market originator products do their very best to convince physicians on the weaknesses that biosimilars may have ..." (Phy1).

“... A biosimilar company has never visited me.

Never! I have never even been visited by a representative of those companies." (Phy2)

“... We have a field force, which are working for more than a year on informing physicians and patients on biosimilars, in the broadest sense of the word ..." (IB2)
“... It is also up to companies that have biosimilars to come forward and to say: this is the concept ..." (IB3)

The representatives of the biosimilar industry also pointed out the ambiguous and insufficient data provided on the website of the Belgian medicines agency (FAGG).

"... If you look at the website of the Belgian medicines agency, for instance, those texts are old, tendentious and over-simplified, not in accordance with the EMA anymore ..." (IB1)

A lack of clinical data supporting safe and effective use of biosimilars was highlighted as an important issue. Part of the concept of biosimilars is their reliance on data of the reference product for efficacy and safety. Biosimilars have to demonstrate clinical equivalence with the reference product for one indication, after which the safety and efficacy can be extrapolated to other indications without additional clinical trials. The approval of marketing authorization by the EMA, however, should assure all stakeholders on the validity this fact.

“... I think there are few clinical studies on biosimilars. This will be the main barrier for physicians to start prescribing ..." (Aut3)

"... I believe there are hardly any clinical studies around biosimilars. That is the main obstacle for the doctors to begin prescribing ..." (Pha3)

"... One of the comments that were made by physicians on existing products was: "we have no experience with those products'. So for the next generation of biosimilars we have also placed studies in Belgium, so there are also Phase II studies in Belgium ..." (IB3)

"... We really look for the most sensitive ways to demonstrate differences. Once this is assured, extrapolation to other indications may be accepted ..." (Aut2).

Some physicians, however, said that this is unfair to originator companies, who spent large amounts of money on clinical trials.

\subsection{Interchangeability and Substitution of Biosimilars}

Interchangeability and substitution of biosimilars is another important issue. To prevent the misuse of these concepts, it is necessary to provide the correct definitions, which were also provided to the interviewees. Interchangeability is an intrinsic property of a product, based on proven full therapeutic equivalence. There are two forms of interchangeability: (i) at the population level, meaning that both products can be used for treatment for the same condition 
in the same population; and (ii) at the individual level, which means that in an individual patient the product can be alternated or switched. Interchangeability at the individual level is a condition for substitution. Interchangeability may lead to switchability: changing the product (e.g. from reference product to biosimilar or vice versa) in a patient during the course of treatment. Substitution is an act, the replacement at the individual patient level of a medicinal product for a similar/therapeutically equivalent product during the course of a treatment without the prescriber's consent, e.g. at the pharmacy level [35].

At the moment, national authorities in Europe bear the responsibility on interchangeability and substitution of biosimilars. One academic suggested this should be the responsibility of the EMA as they possess and evaluated all the data.

“... Personally I think interchangeability should be at the EMA. Because they have all the data, they have analyzed it properly. How can you make a decision if you don't have all clinical data or you haven't analyzed it? I mean, why should national authorities do that again? ..." (Aca1).

Most interviewees agreed that initiation of therapies with biosimilars should be no problem. Switching between the reference product and biosimilars for patients under treatment could cause some problems.

“... For growth hormones, for instance, a chronic treatment of many years, I would not be an advocate of switching. These are patients who need a therapeutic equilibrium ..." (IB2)

“... You shouldn't switch old patients but only new patients. Let's make this clear: if someone receives medicine A, you should continue this therapy with medicine A. Don't start with substitution for these patients ..." (Pat)

“... the prescribing of biosimilars should, in principle, be restricted to naive patients, unless there is a good reason for old patients to switch ..." (Pha1)

"... Patients should be able to continue their therapy with the same biological, unless there is a good therapeutic (no economic) reason to switch ..." (IO1) "... it is best for a patient to stay on the same medicine as long as possible, especially with recombinant medicines ..." (Aca2)

Representatives of the biosimilar industry highlighted that reference products also face interbatch differences, which are comparable with those between the biosimilar and the reference product.

"... If you compare two batches of the same products, they also possess differences. These are not identical, but a biosimilar may vary as much as the batches of innovator products ..." (IB2)

Some stakeholders even went so far as to question the need for biosimilars in Belgium.

“... For me, biosimilars are no necessity in Belgium or in other countries with the same quality of life as Belgium ..." (IO2)

“... We are not asking for biosimilars ... If there is already one product on the market which is good, why would you need five? ..." (Pat)

"... Because the question is: is it necessary to develop biosimilars? ..." (Phy2)

\subsection{Financial Incentives Against Biosimilars}

Financial motives are another major barrier to the uptake of biosimilars in Belgium. Reference biopharmaceuticals have a higher reimbursement limit than lower-priced biosimilars. Most biopharmaceuticals and biosimilars in Belgium are only dispensed in the hospital. The financing of hospitals in Belgium is partly dependent on profits generated by the hospital pharmacy. Manufacturers of originator biopharmaceuticals generally tend to offer discounts, which exceed the price difference of biosimilars, while manufacturers of biosimilars generally do not tend to offer discounts in Belgium. As these discounts are fully recovered by the hospital, the dispensing of the reference biopharmaceutical becomes financially attractive for the hospitals, but not for the third-party payer, a fact that was acknowledged by many of the interviewees.

“... This illustrates the problem of a biosimilar. Even if they offer great discounts, they are still not eligible to be used in the hospital. And the hospital even has a strong argument: why would we use a biosimilar, with all its problems, if we can use an original at the same cost with more discounts? ..." (Aut1)

"So it is not necessary that a generic is the cheapest or a biosimilar is the cheapest." (Pha2)

"... So the hospital benefits from the use of the most expensive products instead of the cheap product. Because then they make more money ..." (IB1)

"How come biosimilars don't work in Belgium? Because originators offer large discounts. And why should you, as a hospital, switch to biosimilars in that case?" (IO2)

"... The physician who works in hospital says: ok, either I make the third-party payer pay or I make my hospital pay. So it's not easy ..." (Aca3)

In addition to the discounts, manufacturers of reference products offer additional benefits to hospitals, so-called 
'fringe benefits'. These benefits include professorships, sponsoring, additional services for physicians, patients, etc. These benefits may result in loyalty of physicians to these companies, thereby, consciously or not, influencing their prescribing behavior.

“... Second way of return on investment can be anything: you can give a lower price but you can also give money for research, sponsor a conference, provide free goods or set up a medical need or compassionate use program ..." (Pha2)

“... They invest in physicians and services, by sponsoring research and providing grants and many more things like that. If you take this away, you are messing with the prescriber ..." (IB2)

“... We like to have a good collaboration with the companies because it helps as many of those companies provide scientific support ..." (Phy1)

Another financial barrier, which might be less obvious, is the additional costs related to the logistics of biosimilars. Biopharmaceuticals are products with a relative short shelflife, regularly on cold chain, which need an appropriate distribution and storage system. If hospitals have to stock both the reference product and the biosimilar, this creates extra logistic needs for this hospital, which can be costly.

"Those are products which are distributed and stored in small quantities. So that is a real challenge in terms of logistics." (IB2)

\section{Discussion}

The uptake of biosimilars in Belgium is almost non-existent and this study has identified three main barriers to the uptake of biosimilars in the market: a lack of confidence towards biosimilars by some stakeholders; uncertainty about interchangeability and substitution of biosimilars; and a hospital financing system that discourages the use of biosimilars. Biosimilars can, however, for the healthcare system as a whole, offer significant savings on pharmaceutical expenditures. Therefore, the Belgian government should remove these barriers and implement a coherent policy to stimulate the uptake of cheaper medicines, like biosimilars.

The Belgian government has recognized the importance of biosimilars to contain escalating pharmaceutical expenditures and has already made some efforts in this respect. For instance, a symposium on "The emergence of biosimilars: which opportunities for patients and the health insurance?" was organized in 2012 by politicians (members of parliament, deputies and senators) to discuss various important aspects related to biosimilars [36].
This study explored the barriers to the uptake of biosimilars in Belgium; however, it was subject to some limitations. The outcome of an interview is dependent on the expertise of both the interviewer and the interviewee on the topic of biosimilars. Moreover, the use of a pre-defined, semi-structured interview guide can be limiting with respect to the issues discussed. Despite these limitations, the barriers that have been identified in this study are in accordance with the conclusions of the Belgian Health Care Knowledge Centre (KCE), which investigated the state of play of biosimilars in Belgium [24]. The main barriers to the uptake of biosimilars identified in that study were grouped into two main categories: clinical barriers related to the knowledge of and attitudes towards biosimilars; and lack of financial incentives and other services for hospitals, prescribers, and patients [24]. These results correspond in part to the outcomes of a survey on good practices for the market uptake of biosimilars in European member states and European Economic Area (EEA) countries. This survey was conducted in 2012 by the European Generic medicines Association (EGA) within the scope of the European Commission Project 'Process on Corporate Responsibility in the Field of Pharmaceuticals Platform Access to Medicines in Europe - Working Group Access and Uptake of Biosimilars'. The main barriers identified in this survey were 'general perception that biosimilar medicines are inferior to innovators'; 'lack of incentives to prescribe/deliver biosimilar medicines'; 'lack of regulation'; and 'reluctance by doctors to switch brands' [37].

Looking back at the theoretic framework that determines a physician's choice to make use of a new innovation, a biosimilar entails uncertainty for all five key innovation criteria (relative advantage, compatibility, complexity, trialability, and observability). The relative advantage of a biosimilar is unclear, and it may even come at a higher cost for the hospital. Compatibility may be low as there is no past experience and the reference product fits the current needs. Complexity is high as the concept of similarity is difficult to understand for physicians and patients. Trialability of a biosimilar is unclear as the individual subscriber will not see an obvious benefit if the biosimilar is only used in a few patients (to try). The observability is also unclear, as biosimilars hardly offer ground-breaking research results [32]. This uncertainty, combined with the affinity with the reference product and the fact that physicians and patients do not like hassle with their medicines, may explain the reservation of Belgian physicians to prescribe biosimilars. Without any real incentive, physicians are unlikely to change their prescription behavior [38].

Scepticism towards biosimilars is a common barrier to their uptake throughout Europe [24, 37]. Doubts on the interchangeability of biosimilars and their originator 
equivalents only strengthen this feeling. Due to the complexities in the development process of biopharmaceuticals, it has become accepted that biosimilars will never be completely identical to their reference products, and clinical trials will be required to assess their safety and effectiveness. However, clinical trials are unsuitable and not sensitive enough to fully identify possible differences in safety or effectiveness [21,39]. Therefore, regulatory agencies might be unlikely to allow substitution for these pharmaceuticals, unless interchangeability has been demonstrated in appropriate additional clinical trials [21].

Nonetheless, a recent meta-analysis found no evidence from clinical trial data or postmarketing surveillance data that switching between different biopharmaceuticals leads to safety concerns [40]. In addition to doubts on interchangeability, biosimilars might also suffer from uncertainty on the cost effectiveness at the time of assessment for reimbursement. In the absence of demonstrated interchangeability, most health authorities tend to request realworld data on the effectiveness of biopharmaceuticals. As these data are not available at the time of submission, biosimilars might be considered by health authorities for coverage with evidence development or risk-sharing agreements [41].

Several policies have already been implemented by the Belgian government to increase the uptake of biosimilars, albeit with only limited success so far. Since 2012, biosimilars in Belgium have been included in low-cost prescribing quotas in ambulatory care [24, 42]. However, biosimilars, like biopharmaceuticals, are mainly prescribed by specialist physicians in hospitals. As a result, the policy has had only limited impact on the uptake of biosimilars in Belgium.

Another policy was the integration of epoetins and growth hormones in the lump-sum reimbursement of pharmaceuticals in hospitals [24, 42]. This is an important step as it recognizes biosimilars and may lead to inclusion of biosimilars in hospital formularies. This policy is, however, more a cost-containment policy as it is hard to see how this would stimulate the uptake of biosimilar epoetins. The policy might even have negative effects on patients. Due to the enormous cost of therapy with epoetins, it is questionable if the limited lump-sum reimbursement will cover all costs. As a result, patients might not receive the proper treatment or hospitalized patients might be discharged, after which they come back for treatment in day care, where the lump sum reimbursement does not apply.

The Belgian government also changed the reimbursement of biosimilars, which are now categorized in reimbursement category F [24, 42]. Pharmaceuticals in this category receive a flat-rate reimbursement, which is generally calculated on the price of the originator reference product. The reimbursement of a biosimilar might subsequently be even higher than the actual price, which might provide a stimulus to use biosimilars. However, this generates no additional savings for third-party payers, as both the reference product and the biosimilars have the same cost. Additionally, when the biosimilar and the reference product have the same price, there is no incentive to use the biosimilar. It might even stimulate manufacturers to offer higher discounts on the reference product to retain their market share. This policy is generally understood to have only a limited impact on the uptake of biosimilars.

European governments have already implemented a variety of policies to increase the use of biosimilars, which seem to have had better success than in Belgium, according to the correspondent market shares [24, 42]. Prescription quotas/targets for biosimilars have been implemented in (regions of) several European countries (e.g. Denmark, Germany, Hungary and Italy) [24, 37]. Automatic substitution of the reference product by a biosimilar and prescribing by international proprietary name for biosimilars is only formally instituted in Romania and not in any other European country. Automatic substitution of biosimilars for other biosimilars is allowed in Germany for some products on a short list of 'bio-identicals', i.e. if they are produced by the same manufacturer with the same manufacturing process [9, 24, 37, 39]. Some European countries have also implemented stand-alone policies to increase the uptake of biosimilars. Norway, for instance, has blocked reimbursement of the reference product of filgrastim $\left(\right.$ Neupogen ${ }^{\circledR}$ ), unless its price is reduced to the reimbursement level of the biosimilar filgrastim (Tevagas$\operatorname{trim}^{\circledR}$ ), which is about $55 \%$ lower. In Austria, an electronic form of the positive list lists biosimilars as alternatives to the reference products together with their prices. A prescription budget should motivate physicians to prescribe biosimilars in the Czech Republic [37]. Hungarian physicians are required to initiate treatment of new, naive patients with biopharmaceuticals that can be, at most, $5 \%$ more expensive than the cheapest available product [5, 19]. Previous research suggests that national policies, which differ from country to country, will have an important impact on the ultimate uptake of biosimilars. Bocquet et al. [43] analyzed the uptake of biosimilar granulocyte colony-stimulating factor in the EU-5 markets (i.e. France, Germany, Italy, Spain, and UK) and concluded that biosimilar uptake, which varies significantly between these countries, is mainly dependent on the local regulatory framework and not on their prices.

In the US, despite the FDA still developing guidelines regarding biosimilars, some states are considering, or have introduced, laws related to the restriction of substitution of biosimilars at the retail pharmacy level [44]. These 'biosimilar laws' stipulate the pharmacists can only substitute a 
biosimilar for originator products if the following requirements are met: the FDA deems the biosimilar 'interchangeable' (which will be the case by definition, as the FDA will not regard it as a biosimilar otherwise); the pharmacist notifies the prescribing physicians and the patient; and the pharmacist keeps a record of the switch for a certain period. Physicians always have, however, the possibility of preventing substitution by ticking a 'do not substitute' box. Some states have already passed this kind of law, while several others have declined [44-47]. This article rounds off with some recommendations to increase the uptake of biosimilars in Belgium.

\section{Recommendations to Increase the Uptake of Biosimilars in Belgium}

The recommendations that are presented to increase the uptake of biosimilars in Belgium are based on known practices, described in the literature, which have shown to work in other countries and could remove the identified barriers to the uptake of biosimilars in Belgium.

\subsection{Inform All Stakeholders on the Concept of Biosimilars}

A negative perception of biosimilars by stakeholders, especially physicians, is a main barrier to their uptake. All stakeholders should receive unbiased information from an independent source on the scientific concept of biosimilars, their registration procedures, and their safety and efficacy. The Generics and Biosimilars Initiative (GaBi), which was founded in 2008, aims to provide a platform for healthcare professionals with scientifically sound, reliable, well-documented, and up-to-date information on generic and biosimilar medicines [48].

\subsection{Reform the Financing of Hospitals}

The current financing system of hospitals is perverse for the cheaper alternative as it works as an incentive to use the pharmaceutical on which the hospital has the biggest profit margin. As originator companies offer high discounts, which exceed the price difference with the biosimilars, the hospital has an apparent economic benefit to use the originator products, at the expense of the third-party payers and society as a whole. This way of financing is non-transparent and may lead to unfair competition.

From 1 July 2013 on, tendering for pharmaceuticals used in the hospital setting has been obligatory in Belgium, regardless of the amount of the assignment [24]. It is, however, to be seen if this practice leads to increased transparency on prices and other services, as the details of these procedures have been available only for the concerned parties and not for the governmental authorities.

\subsection{Develop and Implement Prescription Quota in Hospitals}

Biosimilars have been included in the low-cost prescription quota in ambulatory care. This policy does not affect prescription behavior in hospitals, where most biopharmaceuticals and biosimilars are used, as the policy is limited to ambulatory care. As it is not always easy in a hospital setting to identify the physician responsible, it might be better to set these quotas at the level of the hospital. These quotas should be combined with financial rewards/penalties if the predefined quotas are not met as there will be no incentive to comply otherwise. These quota should apply in particular to patients on chronic treatment, as the largest controversy around switching patients between the reference product and a biosimilar exists for this group. However, this policy will only be effective if the discounts on reference products do not exceed the rewards/penalties in addition to the price of the biosimilar.

Some interviewees also suggested reversing the system and implementing limits on high-cost prescribing. This would not necessarily lead to an increased prescribing of biosimilars but could cause a change of mentality as the prescribing of low-cost medicines would become the standard.

\subsection{Set-Up Patient Registries for Biosimilars}

Lack of data on the safe and effective use of biosimilars is highlighted by physicians as a reason not to prescribe them. As biosimilars do not need to provide the same amount of clinical data as the reference product to obtain marketing authorization, this leads to a vicious circle, which prevents physicians from prescribing biosimilars. Patient registries allow documenting all patient experiences from using biosimilars. These data could break this vicious circle and provide physicians with sufficient data on large numbers of patients.

\subsection{Speed Up the Pricing and Reimbursement Process of Biosimilars}

The Belgian pricing and reimbursement authorities generally ask for additional data on quality, safety, and efficacy of biosimilars before deciding on pricing and reimbursement of these products. The assessment of quality, safety, and efficacy is, however, the responsibility of the EMA during the marketing authorization application. This 'double assessment' seems redundant and delays the market access of biosimilars. 


\section{Conclusion}

The emergence of biosimilars imposes an important challenge for governments. A lack of confidence towards biosimilars by some stakeholders, uncertainty about the interchangeability and substitution of biosimilars, and a hospital financing system that discourages the use of biosimilars appear to be the main reasons for the limited use of biosimilars in Belgium. The government, and also the manufacturers of biosimilars, should take measures to reduce the uncertainties related to biosimilars and to raise confidence. In addition, the financing of hospitals should be reformed and incentives should be developed to stimulate physicians to prescribe biosimilars.

Acknowledgments The authors would like to thank A. Coudron, J. Lambrechts, T. Landrieux, J. Max and A. Rogiers for conducting the interviews and processing and analyzing the data. The authors would like to thank E. Picavet for her assistance during this research. No funding was received to conduct this research. S. Simoens holds the EGA Chair 'European policy towards generic medicines'.Pieter Dylst, Arnold Vulto and Steven Simoens have no conflicts of interest that are directly relevant to the content of this manuscript.

Author contributions The idea of the paper was developed by Steven Simoens and Pieter Dylst, based on a Master's thesis of five pharmacy students. Pieter Dylst is the guarantor for the overall content. The manuscript was prepared by Pieter Dylst. Steven Simoens and Arnold Vulto contributed to this paper by reviewing the manuscript and adding suggestions to improve the paper. All authors revised the draft paper. All authors read and approved the final manuscript.

\section{References}

1. GaBi Online: Generics and Biosimilars Initiative. Biologicals sales have almost doubled since 2006. Available from: http:// www.gabionline.net/Biosimilars/General/Biologicals-sales-havealmost-doubled-since-2006.

2. PipelineReview.com. Blockbuster biologics 2012. R\&D Pipeline News, Special Edition 1/2013. Available from: http://www. pipelinereview.com/index.php/2013050850905/FREE-Reports/ Blockbuster-Biologics-2012.html.

3. Windisch J. The science in biosimilars. Emergence of Biosimilar Medicines Symposium, Belgian Federal Parliament, 22 November 2012. Available from: http://www.sympobiosimilars.be/fr/ docs/Symposium_Biosimilars_22112012_Presentation_3.pdf

4. Weise M, Bielsky M-C, De Smet K, Ehmann F, Ekman N, Narayanan $\mathrm{G}$, et al. Biosimilars-why terminology matters. Nat Biotechnol. 2012;29(8):690-3.

5. Declerck P, Simoens S. A European perspective on the market accessibility of biosimilars. Biosimilars. 2012;2:33-40.

6. European Generic Medicines Association. Biosimilars handbook. 2nd ed. EGA; 2011.

7. Schiestl M, Stangler T, Torella C, Cepeljnik T, Toll H, Grau R. Acceptable changes in quality attributes of glycosylated biopharmaceuticals. Nat Biotechnol. 2011;29(4):310-2.

8. European Commission. Directive 2001/83/EC Art. 10(4) and Part II of the Annex I of Directive 2001/83/EC, as amended. Eudralex. 2013; 1 .
9. European Commission. What you need to know about Biosimilar Medicinal Products? Brussels: European Commission; 2013.

10. Elsevier Clinical Decision Support. Biosimilars-US and international update. Amsterdam: Elsevier; 2012.

11. European Medicines Agency. EMA procedural advice for users of the Centralised Procedure for Similar Biological Medicinal Products applications. EMA/940451/2011. London: European Medicines Agency; 2012.

12. GBI Research. Biosimilars approval pathways in the US and Europe-development and approval of biosimilar mABs may face tough regulatory environment. GBI Research, editor; 2011.

13. Biosimilars - an update. Advisory Committee for Pharmaceutical Science and Clinical Pharmacology, Food and Drug Administration; 2012.

14. Gaffney A. FDA releases fourth biosimilar guidance outlining new types of meetings. Regulatory Focus. 1 Apr 2013. Available from: https://www.raps.org/focus-online/news/news-article-view/ article/3106/fda-releases-fourth-biosimilar-guidance-outliningnew-types-of-meetings.aspx.

15. Simoens S, Verbeken G, Huys I. Biosimilars and market access: a question of comparability and costs? Target Oncol. 2012;7:227-31.

16. Dunne S, Shannon B, Dunne C, Cullen W. A review of the differences and similarities between generic drugs and their originator counterparts, including economic benefits associated with usage of generic medicines, using Ireland as a case study. BMC Pharmacol Toxicol 2013;14(1):1-19.

17. Bourgoin AF, Nuskey B. An outlook on US biosimilar competition. New York: Thomson Reuters; 2013.

18. Grabowski H, Guha R, Salgado M. Biosimilar competition: lessons from Europe. Nat Rev Drug Discov. 2014;13:99-100.

19. Rovira J, Espin J, Garcia L, Olry de Labry A. The impact of biosimilars' entry in the EU market. Andalusia: Andalusian School of Public Health; 2011.

20. Haustein R, de Millas C, Höer A, Häussler B. Saving money in the European healthcare systems with biosimilars. GaBi J. 2012;3-4:120-6.

21. Befrits G. The case for biosimilars: a payer's perspective. GaBi J. 2013;2(1):21.

22. GaBi. US\$67 billion worth of biosimilar patents expiring before 2020. GaBi Online: Generics and Biosimilars Initiative; 2012.

23. European Medicines Agency. European public assessment reports. 2013. Available from: http://www.ema.europa.eu.

24. Lepage-Nefkens I, Gerkens S, Vinck I, Piérart J, Hulstaert F, Farfan-Portet M-I. Barriers and opportunities for the uptake of biosimilar medicines in Belgium. 199. Brussels: KCE Health Services Research; 2013.

25. European Medicines Agency. European Medicines Agency recommends approval of first two monoclonal-antibody biosimilars. 2013. Available from: http://www.ema.europa.eu.

26. Blank T, Netzer T, Hildebrandt W, Vogt-Eisele A, KaszkinBettag M. Safety and toxicity of biosimilars: EU versus US regulation. GaBi J. 2013;2(3):144-50.

27. European Commission. Reimbursement status of authorised biosimilars in MS and EFTA countries. Brussels: European Commission; 2013.

28. IMS. Biosimilar accessible market: size and biosimilar penetration. London; ims I Intelligence Applied; 2012.

29. Sheppard A. Generic medicines, what can the future hold? London: SMi Generics and Patent Strategies; 14 May 2013.

30. Greenland P. Emergence of biosimilar medicines: the biosimilar company point of view. Belgium Federal Parliament Brussels; 22 November 2012.

31. Di Biase S. Biosimilars in the European Market: why and how this is the new frontier? Warsaw: IMS; 2013.

32. Moors E. Challenges for the adoption of future biosimilars. Eur J Hosp Pharmacy Pract. 2007;13(5):57-8. 
33. Pope C, Mays N. Qualitative research in health care. 3rd ed. Oxford: Blackwell Publishing; 2006.

34. QSR Nvivo 9 for Windows. QRS International Pty Ltd; 2006.

35. Crommelin D, Vlieger J, Weinstein V, Mühlebach S, Shah VP, Schellekens H. Different pharmaceutical products need similar terminology. AAPS J. 2014;16(1):11-4.

36. The emergence of biosimilars: which opportunities for patients and the Health Insurance? Belgian Federal Parliament; 22 November 2012.

37. European Generic Medicines Association. EC Project on market access and uptake of biosimilars: survey to members states and EEA countries on biosimilars. Brussels: EGA; 2012.

38. Vulto A. Biosimilars, information gap and barriers to substitution. 9th EGA Symposium on Biosimilar Medicines. London: 2011.

39. Godman B. Health authority perspective on biosimilars. GaBi J. 2013;2(1):10-1.

40. Ebbers H, Muenzberg M, Schellekens H. The safety of switching between therapeutic proteins. Expert Opin Biol Ther. 2012;12(11): 1473-85.
41. Simoens S. Health economics of market access for biopharmaceuticals and biosimilars. J Med Econ. 2009;12(3):211-8.

42. Coudron A, Lambrechts J, Landrieux T, Max J, Rogiers A. Research on market access for biosimilars: detecting obstacles and possible solutions. Leuven: KU Leuven; 2013.

43. Bocquet F, Paubel P, Fusier I, Cordonnier A-L, Le Pen C, Sinègre M. Biosimilar granulocyte colony-stimulating factor uptakes in the EU-5 markets: a descriptive analysis. Appl Health Econ Health Policy. Epub 1 Mar 2014. doi:10.1007/s40258-014-0087-8.

44. Derbyshire M. US state legislation on biosimilars substitution. GaBi J. 2013;2(3):155-6.

45. GaBi. US state biosimilar substitution bill becomes law. $\mathrm{GaBi}$ Online: Generics and Biosimilars Initiative; 2013.

46. GaBi. Fourth US state rejects law restricting biosimilar substitution. GaBi Online: Generics and Biosimilars Initiative; 2013.

47. GaBi. Biotech firms try to limit biosimilar substitution in US. GaBi Online: Generics and Biosimilars Initiative; 2013.

48. Generics and Biosimilars Initiative Online. 2013. Available from: http://www.gabionline.net. 